\title{
HUBUNGAN KEBUTUHAN PETANI DALAM PELAKSANAAN USAHATANI DENGAN SISTEM PENGELOLAAN GILIR GANTI PADI SAWAH
}

(Studi Kasus di Desa Mukai Mudik Kecamatan Siulak Mukai Kabupaten Kerinci)

\section{Relationship Of Farmer Needs in the Farming Management by Paddy Cultivation With The Replace of Shift System}

\author{
Zulfartial Arifin $^{1}$ Rosyani $^{2}$ dan Suandi ${ }^{2}$ \\ 1) Alumni Prodi PKP Jurusan Agribisnis Fakultas Pertanian Unja \\ ${ }^{2)}$ Staf Pengajar Jurusan Agribisnis Fakultas Pertanian Unja \\ Email : khoyhok1990@gmail.com
}

\begin{abstract}
ABSTRAK
Penelitian ini bertujuan 1) untuk mendeskripsikan usahatani padi sawah dengan sistem pengelolaan gilir ganti, 2) untuk mendeskripsikan kebutuhan petani dalam pelaksanaan usahatani padi sawah, dan 3) untuk menganalisis hubungan antara kebutuhan petani dengan usahatani padi sawah dengan sistem pengelolaan gilir ganti. Adapun kebutuhan petani meliputi kebutuhan fisik, kebutuhan rasa aman, kebutuhan sosial, kebutuhan pengakuan, dan kebutuhan aktualisasi diri. Besarnya sampel yang diambil adalah jumlah petani yang mengusahakan padi sawah dengan sistem pengelolaan gilir ganti yang tergabung dalam gabungan kelompok tani Tengah Padang dengan total keseluruhan sampel adalah 70 orang. Data yang diperlukan dalam penelitian ini adalah data primer dan data sekunder. Untuk mencapai tujuan 1 dan 2 dilakukan analisis kualitatif, sedangkan untuk memenuhi tujuan ke 3 dilakukan dengan uji Chi-Square (Siegel, 1997) yang kontingensi $2 \times 3$. Hasil penelitian ini menunjukan bahwa sistem gilir ganti masih dipertahankan di daerah penelitian meskipun manfaat dari sistem ini berdampak sangat kecil terhadap pengguna sistem. kebutuhan petani di daerah penelitian pada umumnya tergolong tinggi, terdapat 5 indikator kebutuhan petani dalam pelaksanaan usahatani padi sawah dengan sistem pengelolaan gilir ganti padi sawah: 1) kebutuhan fisik, 2) kebutuhan rasa aman, 3) kebutuhan sosial, 4) kebutuhan pengakuan, 5) kebutuhan aktualisasi diri. Selanjutnya, kebutuhan petani dalam pelaksanaan usahatani berhubungan secara nyata dengan pelaksanaan sistem pengelolaan gilir ganti padi sawah
\end{abstract}

Kata Kunci : Kebutuhan, Pengelolaan, sistem gilir ganti, Padi sawah

\section{ABSTRACT}

This research aims 1 ) to describe the farming of paddy with a shift change management system, 2) to describe the needs of farmers in the implementation of the paddy rice farming, and 3) analyzing the relationship between the needs of farmers with paddy farming by changing shift management system. The farmer needs include physical needs, safety needs, social needs, the need for recognition, and self-actualization needs. The sample was taken by the number of farmers that do cultivation paddy farming by replace the shift system in the Tengah Padang with the total sample is 70 . The necessary data in this research were primary data and secondary data. To achieve the objectives 1 and 2 performed qualitative analysis, while to meet the goal to 3 performed by Chi-Square test (Siegel, 1997) that contingency $2 \times 3$. These results indicate that the system shifts the dressing is retained in the study area although the benefits of these systems have very little impact on system users. the needs of farmers in the research area in general is high, there are five indicators of the needs of farmers in paddy farming with the management system shifts replace paddy: 1) physical needs, 2) safety needs, 3) social needs, 4) need for recognition, 5) self-actualization needs. Furthermore, the needs of farmers in the implementation of farm-related significantly to the implementation of management systems replace paddy cultivation.

Keywords: Needs, Management, replace the shift system, rice paddy. 


\section{PENDAHULUAN}

Peran subsektor tanaman pangan dalam perekonomian masih sangat penting dan strategis. Peranan penting dan strategis ini terutama dalam hal meningkatkan produksi untuk dapat mencukupi kebutuhan pangan, seperti padi. Program peningkatan ketahanan pangan diarahkan untuk dapat memenuhi kebutuhan pangan masyarakat dalam negeri dari pangan nasional. Berbagai upaya telah di tempuh pemerintah melalui pengamatan pengamanan lahan, peningkatan mutu intensifikasi serta optimalisasi dan perluasan areal pertanian. Salah satu bahan pangan nasional yang di upayakaan ketersediaanya tercukupi sepanjang tahun adalah beras yang menjadi makanan pokok bagi sebagian besar penduduk Indonesia.

Pengelolaan yang baik dan sempurna merupakan kunci sukses dalam melakukan usahatani. Pengelolaan usahatani merupakan pilihan/pertimbangan petani dalam mengkombinasikan sumber daya yang terbatas dan pengetahuan yang dimilikinya, untuk memilih dan membuat keputusan dalam mengusahakan lahan pertaniannya. Pengelolaan itu sendiri menurut Hernanto (1991) adalah kemampuan petani dalam menentukan dan mengkoordinasikan faktor-faktor produksi yang dikuasainya sebaik-baiknya dan mampu memberikan produksi pertanian.

Usahatani adalah usaha yang dilakukan seseorang dalam mengkoordinir faktorfaktor produksi berupa lahan dan alam sekitarnya sebagai modal sehingga memberikan manfaat yang sebaik-baiknya. Sebagai ilmu pengetahuan, ilmu usahatani merupakan ilmu yang mempelajari cara-cara petani mnentukan, mengorganisasikan, mengkoordinasikan penggunaan factor-faktor produksi seefektif dan seefisien mungkin sehingga usaha tersebut memberikan pendapatan semaksimal mungkin.

Kabupaten Kerinci menerapkan kebudayaan dalam melakukan usahatani padi sawah, Dimana sampai sekarang ini kebudayaan tersebut masih tetap dipertahankan oleh petani, salah satu kebudayaan yang masih di pertahankan yaitu sistem gilir ganti. Sistem gilir ganti adalah pola penguasaan tanah sawah yang dijalankan secara bergantian dalam menggunakan dan pemakainnya oleh ahli waris tanah sawah guna mendapatkan hasilnya. Adanya sistem ini adalah pengaruh sistem kewarisan. Banyaknya peserta dan persilangan gilir ganti sawah mempengaruhi pergerakan sistem dan masa tunggu setiap peserta untuk mendapatkan giliranya.

Kecamatan Siulak Mukai merupakan salah satu kecamatan yang ada di Kabupaten Kerinci yang masih menerapkan kebudayaan sistem gilir ganti pada usahatani padi sawah. Desa Mukai Mudik merupakan sebuah desa dari kecamatan Siulak Mukai yang menjadi lokasi daerah penelitian. Bedasarkan survey awal, penulis dapat menarik kesimpulan bahwa dari penerapan sistem gilir ganti ini memiliki beberapa manfaat, yaitu untuk melestarikan kebiasaan atau budaya dari nenek moyang yang telah dilakukan turun menurun, untuk mempererat hubungan keluarga, dan menjaga keutuhan warisan keluarga.

\section{METODE PENELITIAN}

Penelitian ini akan dilaksanakan di Desa Mukai Mudik Kecamatan Siulak Mukai Kabupaten Kerinci. Pemilihan lokasi penelitian ini dilakukan dengan sengaja (purposive). Desa Mukai Mudik dipilih sebagai lokasi penelitian karena belum pernah dilakukan penelitian tentang motivasi petani mempertahakan sistem gilir ganti pengelolaan usahatami padi sawah. Desa Mukai Mudik adalah desa dari Kecamatan Siulak Mukai yang merupakan pemekaran dari Kecamatan Siulak. Adapun yang menjadi objek dari penelitian ini adalah Desa Mukai Mudik. Penelitian ini dilaksanakan dari 29 juni sampai dengan 29 juli 2015 
Untuk kebutuhan penelitian ini ada dua macam data dan informasi yang dibutuhkan dalam penelitaian ini, yaitu data dan informasi primer, data dan informasi sekunder. Data dan informasi primer adalah data yang diperoleh secara langsung dari informan dan melalui wawancara mendalam (in-depth interview), wawancara terstruktur serta observasi. Informan merupakan sasaran wawancara dalam mendapatkan keterangan atau data tertentu untuk keperluan informasi dalam penelitian, yang menjadi informan adalah kepala desa, sekretaris desa, tokoh masyarakat (orang yang dianggap mengetahui dan memahami kondisi daerah penelitian).

Objek pengamatan adalah petani yang tergabung dalam 10 kelompok tani berjumlah 236 anggota yang mengusahakan sistem gilir ganti pada pengelolaan usahatani padi sawahnya. Metode penarikan sampel dilakukan secara acak sederhana (simple random sampling), yaitu setiap populasi memiliki kesempatan yang sama untuk dipilih sebagai sampel dengan cara mengambil sampel dari anggota populasi secara acak dalam anggota populasi tersebut. (Singarimbun dan Efendi, 1995).

Data yang diperoleh dari hasil penelitian ini dianalisis secara deskriptif dengan menggunakan tabulasi frekuensi dan persentase, baik data motivasi maupun data sistem gilir ganti. Untuk mencapai tujuan 1 dan 2 dilakukan analisis kualitatif, sedangkan untuk memenuhi tujuan ke 3 dilakukan dengan uji Chi-Square (Siegel, 1997) yang kontingenya $2 \times 3$.

\section{HASIL DAN PEMBAHASAN}

\section{Deskripsi Responden}

Karakteristik seseorang merupakan ciri khas yang mengandung diferensiasi dan mewakili citra seseorang sehingga dapat membedakannya dengan orang lain. Identitas petani sampel dalam penelitian ini dibatasi pada beberapa karakteristik yang diperkirakan dapat mempengaruhi kemauan dan kemampuan petani dalam berusahatani. Identitas petani sampel dalam penelitian ini meliputi: nama, alamat, umur, tingkat pendidikan, pengalaman berusahatani, jumlah anggota keluarga, dan luas lahan.

Berdasarkan data petani menunjukkan bahwa umur responden terbesar berada pada kelompok umur 33 - 38 tahun sebanyak 30 orang, sedangkan yang terendah berada pada kelompok umur 45-50 tahun sebanyak 2 orang. Maka dapat dikatakan bahwa didaerah penelitian termasuk usia produktif dalam menjalankan usahatani, sehingga memungkinkan untuk mengelola dan mempertahankan usahataninya.

Pendidikan yang dimaksud adalah pendidikan formal yang diikuti oleh petani. persentase terbesar pendidikan petani adalah tamat SD yaitu sebesar 41 persen atau sebanyak 29 orang., dan persentase terkecil sebesar $6,3 \%$ atau sebanyak 4 orang yang tamat Sarjana. Maka dapat disimpulkan bahwa tingkat pendidikan yang dimiliki petani tergolong rendah.

Jumlah tanggungan keluarga adalah anggota keluarga atau semua orang yang tinggal dalam satu rumah ataupun diluar rumah yang menjadi tanggungan keluarga . anggota keluarga terdiri dari suami, istri, anak-anak, famili atau keluarga yang menjadi tanggungan keluarga.banyaknya anggota keluarga berkaitan dengan tingkat kepuasan seseorang dalam bekerja dan memenuhi kebutuhan. Jumlah anggota keluarga yang paling banyak terdapat pada selang $2-5$ orang sebanyak 58 orang atau sebesar 83 persen dari jumlah sampel.

Pengalaman dalam berusahatani juga dapat mendorong petani agar tetap mengelola usahatani agar tetap berkesinambungan. Pengalaman petani mengenai kegagalan dan keberhasilan selama mengelola usahatani akan memperkaya pengetahuannya. Pengalaman berusahatani yang terbanyak yaitu pada selang 10-17 tahun yaitu sebanyak 28 orang atau sebesar 40 persen.

Lahan merupakan salah satu faktor produksi dalam berusahatani. Luas lahan yang dimiliki petani dapat mempengaruhi tingkat kerja dan hasil produksi. Luas lahan 
usahatani yang paling banyak adalah pada selang $0,4-0,5$ ha sebanyak 36 orang, yang terendah terdapat pada selang $0,6-0,7$ ha atau sebanyak 6 orang.

\section{Kebutuhan Petani Dalam Menerapkan Usahatani Padi Sawah Dengan Sistem Pengelolaan Gilir Ganti}

Dalam pengambilan keputusan melakukan kegiatan usahatani padi sawah tidak terlepas dari kebutuhan, dalam artian bahwa ada sebuah dorongan yang timbul dari dalam diri untuk melaksanakan kegiatan tersebut. Kebutuhan petani dalam mempertahankan usahatani padi sawah dapat dilihat dari 5 komponen, yaitu kebutuhan fisik, kebutuhan rasa aman, kebutuhan sosial, kebutuhan pengakuan dan kebutuhan aktualisasi diri.

Kebutuhan petani dalam pelaksanaan usahatani padi sawah di Desa Mukai Mudik memiliki frekuensi dan persentase, untuk lebih jelasnya dapat dilihat pada Tabel 1 berikut:

Tabel 1. Distribusi Frekuensi Kebutuhan Petani Dalam Pelaksanaan Usahatani Padi Sawah di Desa Mukai Mudik Kecamatan Siulak Mukai Kabupaten Kerinci

\begin{tabular}{ccccc}
\hline No & Skor & Kategori & Frekuensi & Persentase (\%) \\
\hline 1 & $156-184$ & Tinggi & 25 & 35.7 \\
2 & $130-155$ & Sedang & 25 & 35.7 \\
3 & $102-129$ & Rendah & 20 & 28.6 \\
\hline & Jumlah & & $\mathbf{7 0}$ & $\mathbf{1 0 0}$ \\
\hline
\end{tabular}

Tabel 1 menunjukkan bahwa kebutuhan petani dalam pelaksanaan usahatani padi sawah cenderung berimbang antara tinggi dan sedang yaitu berkisar 35,7 atau sebanyak 25 responden. Hal ini jika kelima unsur kebutuhan tersebut digabungkan.

Jika kebutuhan dipisah menurut unsur-unsurnya diketahui ternyata petani cenderung termotivasi pada kebutuhan pengakuan dimana $74,28 \%$ pada kebutuhan ini. Untuk rincian lebih jelas dapat dilihat pada Tabel 2.

Tabel 2. Persentase Capaian Kebutuhan Petani Dalam Pelaksanan Usahatani Padi Sawah Di Desa Mukai Mudik Kecamatan Siulak Mukai Kabupaten Kerinci

\begin{tabular}{clc}
\hline No & \multicolumn{1}{c}{ Indikator Kebutuhan } & Persentase Capaian \% \\
\hline 1 & Kebutuhan Fisik & 73 \\
2 & Kebutuhan Rasa Aman & 71.28 \\
3 & Kebutuhan Sosial & 68.42 \\
4 & Kebutuhan Pengakuan & 75.77 \\
5 & Kebutuhan Aktualisasi Diri & 74 \\
\hline
\end{tabular}

Berdasarkan Tabel 2, dapat dijelaskan bahwa persentase capaian kebutuhan tertinggi terletak pada kebutuhan pengakuan sebesar 75,77\%, dan paling rendah terletak pada kebutuhan sosial sebesar $68,42 \%$. Dengan demikian dapat dikatakan kebutuhan pengakuan yang mendominasi petani dalam pelaksanaan usahatani padi sawah.

\section{Kebutuhan Petani Dalam Pelaksanaan Usahatani Padi Sawah Berdasarkan Kebutuhan Fisik}

Kebutuhan fisik adalah aspek yang berkenaan dengan kebutuhan sandang, pangan, dan papan. Kebutuhan fisik sangat erat kaitannya dengan kehidupan sehari-hari yang tidak pernah terlepas dari kehidupan masyarakat (petani).

Tabel 3. Skor Kebutuhan Fisik Petani Dalam Mempertahankan Usahatani Padi Sawah Di Desa Mukai Mudik

\begin{tabular}{ccccc}
\hline No & Skor & Kategori & Frekuensi & Persentase (\%) \\
\hline 1 & $32-38$ & Tinggi & 32 & 45.7
\end{tabular}




\begin{tabular}{ccccc}
2 & $23-31$ & Sedang & 26 & 37 \\
3 & $14-22$ & Rendah & 12 & 17.3 \\
\hline & Jumlah & & $\mathbf{7 0}$ & $\mathbf{1 0 0}$ \\
\hline
\end{tabular}

Berdasarkan Tabel 3, dapat dijelaskan bahwa kebutuhan petani secara fisik cenderung berada pada kategori tinggi $45.7 \%$, sedangkan kategori rendah sebesar $12 \%$ dari jumlah sampel. Yang artinya kebutuhan fisik merupakan salah satu indikator yang menyebabkan petani melaksanakan usahatani dengan sistem pengelolaan gilir ganti padi sawah.

\section{Kebutuhan Petani Dalam Pelaksanaan Usahatani Padi Sawah Berdasarkan Kebutuhan Rasa Aman.}

Setelah kebutuhan fisik terpenuhi sekarang kebutuhan akan rasa aman sangat mempengaruhi. Kebutuhan akan rasa aman adalah kebutuhan akan keamanan sewaktu bekerja, perasaan aman yang menyangkut masa depan untuk menciptakan rasa aman dari ancaman-ancaman dari luar yang mungkin terjadi, apakah itu ancaman dari orang lain , alam ataupun dari faktor lainnya

Tabel 4. Skor Kebutuhan Rasa Aman Dalam Pelaksanaan Usahatani Padi Sawah Di Desa Mukai Mudik

\begin{tabular}{ccccc}
\hline No & Skor & Kategori & Frekuensi & Persentase (\%) \\
\hline 1 & $32-38$ & Tinggi & 29 & 41.5 \\
2 & $24-31$ & Sedang & 28 & 40 \\
3 & $16-23$ & Rendah & 13 & 18.5 \\
\hline & Jumlah & & $\mathbf{7 0}$ & $\mathbf{1 0 0}$ \\
\hline
\end{tabular}

Berdasarkan Tabel 4, dapat dijelaskan bahwa motivasi petani berdasarkan kebutuhan rasa aman berada pada kategori tinggi, yaitu sekitar $41,5 \%$ petani. Dapat dilihat bahwa kebutuhan rasa aman menjadi indikator petani dalam pelaksanaan usahatani padi sawah dengan sistem gilir ganti walaupun perbedaan frekuensi antara tinggi dan sedang hanya berselisih satu responden.

\section{Kebutuhan Petani Dalam Pelaksanaan Usahatani Padi Sawah Berdasarkan Kebutuhan Sosial}

Kebutuhan sosial adalah dorongan untuk menjadi bagian dari orang lain, dan keinginan untuk membantu orang lain, ingin diikut sertakan, dan di hargai oleh orang lain.

Tabel 5. Skor Kebutuhan Sosial Dalam Pelaksanaan Usahatani Padi Sawah Di Desa Mukai Mudik

\begin{tabular}{ccccc}
\hline No & Skor & Kategori & Frekuensi & Persentase (\%) \\
\hline 1 & $32-38$ & Tinggi & 26 & 37 \\
2 & $23-31$ & Sedang & 22 & 31.5 \\
3 & $14-22$ & Rendah & 22 & 31.5 \\
\hline & Jumlah & & $\mathbf{7 0}$ & $\mathbf{1 0 0}$
\end{tabular}

Tabel 5 menunjukkan bahwa kebutuhan petani secara sosial berada pada kategori tinggi dengan persentase $37 \%$ dari jumlah sampel, yang berarti kebutuhan sosial menjadi indikator terendah petani dalam pelaksanaan uasahatani padi sawah dengan sistem pengelolaan gilirganti padi sawah.

Kebutuhan Petani Dalam Pelaksanaan Usahatani Padi Sawah Berdasarkan Kebutuhan Akan Pengakuan 
Kebutuhan pengakuan tak hanya menjadi bagian dari masyarakat, tapi lebih jauh dari itu, yaitu diakui/dihormati/dihargai orang lain karena kemampuannya atau kekuatannya.

Tabel 6. Skor Kebutuhan Akan Pengakuan Dalam Pelaksanaan Usahatani Padi Sawah Di Desa Mukai Mudik

\begin{tabular}{ccccc}
\hline No & Skor & Kategori & Frekuensi & Persentase (\%) \\
\hline 1 & $34-40$ & Tinggi & 29 & 40 \\
2 & $25-33$ & Sedang & 23 & 35 \\
3 & $16-24$ & Rendah & 18 & 25 \\
\hline & Jumlah & & $\mathbf{7 0}$ & $\mathbf{1 0 0}$ \\
\hline
\end{tabular}

Dari Tabel 6 dapat dilihat bahwa persentase kebutuhan petani mempertahankan usahatani padi sawah berdasarkan kebutuhan pengakuan cenderung besar yaitu sebesar $40 \%$, yang menjadi indikator petani melaksanakan usahatani dengan sistem pengelolaan gilir ganti padi sah.

\section{Kebutuhan Petani Dalam Pelaksanaan Usahatani Padi sawah Berdasarkan Kebutuhan Aktualisasi Diri}

Kebutuhan aktualisasi diri adalah dorongan dari dalam diri untuk menunjukkan kemampuan/minat/atau potensi diri ke dalam bentuk yang lebih nyata dalam kehidupannya. Ini ditandai dengan hasrat individu untuk menjadi orang yang sesuai dengan keinginannya.

Tabel 7.Skor Kebutuhan Aktualisasi Diri Dalam Pelaksanaan Usahatani Padi Sawah Di Desa Mukai Mudik

\begin{tabular}{ccccc}
\hline No & Skor & Kategori & Frekuensi & Persentase (\%) \\
\hline 1 & $34-40$ & Tinggi & 26 & 37 \\
2 & $25-33$ & Sedang & 23 & 36 \\
3 & $16-24$ & Rendah & 21 & 27 \\
\hline & Jumlah & & $\mathbf{7 0}$ & $\mathbf{1 0 0}$ \\
\hline
\end{tabular}

Tabel 7 menunjukkan bahwa kebutuhan petani dalam pelaksanaan usahatani padi sawah tidak terlalu tinggi, yaitu sebesar 37\% dari jumlah petani sampel. Ini membuktikan bahwa kebutuhan aktualisasi diri menjadi indikator terendah bersama dengan kebutuhan sosial.

\section{Asal Usul Sawah Gilir Ganti}

Menurut Irsan Idris (2011), pada awalnya sawah gilir ganti adalah tanah hak milik perseorangan yang diperoleh karena usaha sendiri dengan membuat atau membeli sawah orang lain. Namun bisa juga bersalah dari harta warisan,hibah atau pemberian seseorang karena alasan tertentu. Dalam masyarakat Kerinci, untuk membuat sebidang tanah sawah biasanya seseorang menggunakan tanah sawah yang berasal dari tanah ulayat dusun atau dari tabah yang dibelinya dari orang lain lalu di jadikan sawah. Berdasarkan wawancara dengan pembuka-pembuka adat, dapat disimpulkan bahwa sebidang tanah sawah gilir ganti berasal dari.

1. Tanah ulayat.

Tanah ulayat menurut hukum adat di Kerinci adalah tanah masyarakat adat yang berada dalam wilayah dimana masyarakat bermukim. Setiap tanah ulayat mempunyai batas-batas tertentu yang diketahui persis oleh masyarakat adat setempat,biasanya dengan tanda alami seperti sungai,danau, pohon, parit dan dalam bentuk lainnya tanah ini dapat berupa tanah hutan, tanah belukar dan tanah rawa.

2. Pembagian harta warisan. 
Dalam kelompok harta warisan, tanah sawah, rumah dan ladang merupakan harta pusaka. Oleh sebab itu dalam setiap pewarisan biasanya selalu terdapat tanah sawah. Bila setiap ahli waris membawa bagian dari warisan yang diterimanya ke dalam keluarga, maka berarti terdapat tanah sawah yang akan diwariskan kepada generasi berikutnya yang berasal dari harta warisan pihak ayah dan ibu.

\section{Tanggapan Responden Terhadap Sistem Gilir Ganti}

Berikut ini adalah gambaran dalam sistem pengelolaan gilir ganti padi sawah.yang disajikan pada Tabel 8 berikut ini:

Tabel 8. Distribusi Frekuensi Responden Berdasarkan Sistem Pengelolaan Gilir Ganti Padi Sawah.

\begin{tabular}{clc}
\hline No. & \multicolumn{1}{c}{ Kategori } & Persentase \% \\
\hline 1. & Dapat memenuhi kebutuhan keluarga & $65 \%$ \\
2. & Meningkatkan perekonomian & $30 \%$ \\
3. & Mempertahankan silsilah keluarga & $81 \%$ \\
4. & Puas dengan yang diperoleh & $36 \%$ \\
5. & Akan mempertahankan gilir ganti & $100 \%$ \\
\hline
\end{tabular}

Tabel 8 dapat dijelaskan bahwa:

1. Dapat memenuhi kebutuhan keluarga

Dari pertanyaan terbuka yang di ajukan kepada tentang motivasi menurut manfaat gilir ganti, sebanyak 45 orang atau $65 \%$ dari total responden menjawab bahwa sawah yang mereka gilir gantikan dapat memenuhi kebutuhannya.

2. Kurang meningkatkan perekonomian keluarga

Adapun hasil dari sawah yang digilirkan oleh petani, hanya memenuhi kebutuhannya saja, kurang dapat meningkatkan perekonomian keluarga. Dari hasil interview kepada petani, didapat sebanyak 52 responden atau sekitar $74 \%$ menjawab kurang meningkatkan perekonomiannya. Hanya sebagian responden yang menjawab dapat meningkatkan perekonomian keluarga, yaitu sebesar 18 responden atau $26 \%$.

3. Mempertahankan silsilah keluarga

Sebagian besar responden menjawab menjalankan sistem gilir ganti untuk menjaga silsilah keluarga, sebagai tanda ikatan kekeluargaan (kekerabatan), yaitu sebanyak $41 \%$ atau 29 responden.

4. Tidak puas dengan hasil sawah gilir ganti

Sebanyak 36 atau 52\% responden mengaku tidak puas dengan hasil yang diperoleh dari sawah gilir ganti. Hal ini dikarenakan sawah gilir ganti hanya mampu memenuhi kebutuhan pangan, tidak dapat meningkatkan perekonomian, dimana kebutuhan lain yang tidak terpenuhi seperti kebutuhan sandang dan papan.

5. Akan terus menjalankan sistem gilir ganti

$100 \%$ responden menjawab akan terus menjalankan sistem gilir ganti, ini dikarenakan sistem gilir ganti adalah satu sistem adat yang tidak bisa di tinggalkan, terlepas dari banyaknya kekurangan-kekurangan dari menjalankan sistem ini.

\section{Hubungan Kebutuhan Petani Dalam pelaksanaan Usahatani Dengan Sistem Pengelolaan Gilir Ganti Padi Sawah}

Kebutuhan petani dalam Menjalankan sistem gilir ganti padi sawah tidak terlepas dari pengetahuan mereka terhadap budidaya padi sawah. Analisis hubungan antara aspek motivasi dengan sistem gilir ganti pada padi sawah dijelaskan pada Tabel 10:

Tabel 10. Kontingensi Kebutuhan Petani Dalam Pelaksanaan Usahatani Dengan Sistem Gilir Ganti Padi sawah

\begin{tabular}{cccc} 
Sistem Gilir & \multicolumn{3}{c}{ Kebutuhan Petani } \\
Ganti
\end{tabular}




\begin{tabular}{ccccc}
\hline Tinggi & 21 & 16 & 15 & 52 \\
Rendah & 4 & 9 & 5 & 18 \\
Jumlah & 25 & 25 & 20 & 70 \\
\hline
\end{tabular}

Tabel 10 memperlihatkan hubungan kebutuhan petani dengan sistem gilir ganti padi sawah di daerah penelitian, yaitu ada kecenderungan jika kebutuhan tinggi maka tingkat pelaksanaan usahatani dengan sistem pengelolaan gilir ganti tinggi.

Berdasarkan uji statistik non parametrik dengan menggunakan uji Chi-square di peroleh nilai $X^{2}$ hit $=30,38$ dengan nilai $X^{2}$ tabel $(\alpha=5 \% \mathrm{db}=2)=5,99$. Karena $X^{2}$ hit $=30,38>X^{2}$ tabel $(\alpha=5 \% \mathrm{db}=2)=5,99$ maka diputuskan tolak $H_{0}$ (terima $H_{1}$ ), yang berarti tinggi rendahnya kebutuhan petani mempengaruhi tinggi rendahnya pelaksanaan usahatani dengan sistem pengelolaan gilir ganti padi sawah. Derajat kontingensi kebutuhan petani dengan pelaksanaan usahatani dengan sistem pengelolaan gilir ganti padi sawah adalah $C_{\square i t}=0,55$ dan $C_{\text {maks }}=0,8164$. Hal ini artinya derajat kecendrungan kebutuhan petani dengan pelaksanaa usahatani dengan sistem pengelolaan gilir ganti padi sawah adalah 55 persen. Kecendrungan hubungan antara kebutuhan petani dengan pelaksanaan usahatani dengan sistem pengelolaan gilir ganti padi sawah tergolong kuat dimana nilai $\mathrm{C}=0,55$ (berada antara $0,4082-0,8164$ ). Sedangkan pengukuran derajat korelasi antara perbedaan kebutuhan petani dengan pelaksanaan usahatani dengan sistem pengelolaan gilir ganti padi sawah diperoleh $\mathrm{r}=06738$. Hasil pengujian terhadap koefisien $\mathrm{r}$ diperoleh $T_{\square i t}=7,52$. Karena $T_{\square i t}=7,52 T_{\text {tabsl }} \quad(\alpha / 2=5 \% \mathrm{db}=68)=1,99$ maka tolak $H_{0}$ ( terima $H_{1}$ ) artinya kebutuhan petani dalam pelaksanaan usahatani padi sawah berhubungan secara nyata dengan sistem pengelolaan gilir ganti padi sawah di Desa Mukai Mudik.

\section{Hubungan Kebutuhan Petani Berdasarkan Fisik Dengan Sistem Pengeloalaan Gilir ganti Padi sawah.}

Berdasarkan hasil penelitian yang dilakukan mengenasi hubungan kebutuhan petani berdasarkan kebutuhan fisik dengan pelaksanaan usahatani dengan sistem pengelolaan gilir ganti padi sawah dapat lihat pada Tabel 11.

Tabel 11. Kontingensi Kebutuhan Petani Berdasarkan Fisik Dengan Sistem Pengelolaan Gilir Ganti Padi Sawah

\begin{tabular}{ccccc}
\hline Sistem Gilir & \multicolumn{3}{c}{ Kebutuhan Petani } & \multirow{2}{*}{ Jumlah } \\
\cline { 2 - 4 } Ganti & Tinggi & Sedang & Rendah & \\
\hline Tinggi & 25 & 19 & 8 & 52 \\
Rendah & 7 & 7 & 4 & 18 \\
Jumlah & 32 & 26 & 12 & 70 \\
\hline
\end{tabular}

Tabel 11 memperlihatkan hubungan kebutuhan petani berdasarkan kebutuhan fisik dengan sistem pengelolaan gilir ganti padi sawah di daerah penelitian, yaitu ada kecendrungan jika kebutuhan fisik tinggi maka tingkat pelaksanaan usahatani dengan sistem pengelolaan gilir ganti tinggi.

Berdasarkan uji statistik non parametrik dengan menggunakan uji Chi-square di peroleh nilai $X^{2}$ hit $=46,11$ dengan nilai $X^{2}$ tabel $(\alpha=5 \% \mathrm{db}=2)=5,99$. Karena $X^{2}$ hit $=46,11>X^{2}$ tabel $(\alpha=5 \% \mathrm{db}=2)=5,99$ maka diputuskan tolak $H_{0}$ (terima $H_{1}$ ), yang berarti tinggi rendahnya kebutuhan mempengaruhi tinggi rendahnya pelaksanaan usahatani dengan sistem pengelolaan gilir ganti padi sawah. Derajat kontingensi kebutuhan petani dengan pelaksanaan usahatani dengan sistem pengelolaan gilir ganti padi sawah adalah $C_{\text {hit }}=0,63$ dan $C_{\text {maks }}=0,8164$. Hal ini artinya derajat kecendrungan kebutuhan petani dengan pelaksanaan usahatani dengan sistem pengelolaan gilir ganti padi sawah adalah 63 persen. Kecendrungan hubungan antara kebutuhan petani dengan 
pelaksanaan usahatani dengan sistem pengelolaan gilir ganti padi sawah tergolong kuat dimana nilai $C=0,63$ (berada antara $0,4082-0,8164$ ). Sedangkan pengukuran derajat korelasi antara perbedaan kebutuhan petani dengan pelaksanaan usahatani dengan sistem pengelolaan gilir ganti padi sawah diperoleh $r=0,77$. Hasil pengujian terhadap koefisien $\mathrm{r}$ diperoleh $T_{\text {hit }}=9,95$. Karena $T_{\text {hit }}=9,95 T_{\text {tabsl }} \quad(\alpha / 2=5 \% \mathrm{db}=68)=1,99$ maka tolak $H_{0}$ ( terima $H_{1}$ ) artinya kebutuhan petani dalam pelaksanaan usahatani padi sawah berhubungan secara nyata dengan sistem pengelolaan gilir ganti padi sawah di Desa Mukai Mudik.

\section{Hubungan Kebutuhan Petani Berdasarkan Rasa Aman Dengan Sistem Pengelolaan Gilir Ganti Padi Sawah.}

Berdasarkan hasil penelitian yang dilakukan mengenasi hubungan kebutuhan petani berdasarkan kebutuhan rasa aman dengan pelaksanaan usahatani dengan sistem pengelolaan gilir ganti padi sawah dapat lihat pada Tabel 12:

Tabel 12. Kontingensi Kebutuhan Petani Berdasarkan Rasa Aman Dengan Sistem Pengelolaan Gilir Ganti Padi Sawah.

\begin{tabular}{ccccc}
\hline Sistem Gilir & \multicolumn{3}{c}{ Motivasi Petani } & \multirow{2}{*}{ Jumlah } \\
\cline { 2 - 4 } Ganti & Tinggi & Sedang & Rendah & \\
\hline Tinggi & 23 & 18 & 11 & 52 \\
Rendah & 6 & 10 & 2 & 18 \\
Jumlah & 29 & 28 & 13 & 70 \\
\hline
\end{tabular}

Tabel 12 memperlihatkan hubungan kebutuhan petani berdasarkan kebutuhan rasa aman dengan sistem pengelolaan gilir ganti padi sawah di daerah penelitian, yaitu ada kecendrungan jika kebutuhan rasa aman tinggi maka tingkat pelaksanaan usahatani dengan sistem pengelolaan gilir ganti tinggi.

Berdasarkan uji statistik non parametrik dengan menggunakan uji Chi-square di peroleh nilai $X^{2}$ hit $=30,37$ dengan nilai $X^{2}$ tabel $(\alpha=5 \% \mathrm{db}=2)=5,99$. Karena $X^{2}$ hit $=30,37>X^{2}$ tabel $(\alpha=5 \% \mathrm{db}=2)=5,99$ maka diputuskan tolak $H_{0}$ (terima $H_{1}$ ), yang berarti tinggi rendahnya kebutuhan petani mempengaruhi tinggi rendahnya pelaksanaan usahatani dengan sistem pengelolaan gilir ganti padi sawah. Derajat kontingensi kebutuhan petani dengan pelaksanaan usahatani dengan sistem pengelolaan gilir ganti padi sawah adalah $C_{\text {hit }}=0,55$ dan $C_{\text {maks }}=0,8164$. Hal ini artinya derajat kecendrungan kebutuhan petani dengan pelaksanaan usahatani dengan sistem pengelolaan gilir ganti padi sawah adalah 55 persen. Kecendrungan hubungan antara kebutuhan petani dengan pelaksanaan usahatani dengan sistem pengelolaan gilir ganti padi sawah tergolong kuat dimana nilai $\mathrm{C}=0,55$ (berada antara $0,4082-0,8164$ ). Sedangkan pengukuran derajat korelasi antara perbedaan kebutuhan petani dengan pelaksanaan usahatani dengan sistem pengelolaan gilir ganti padi sawah diperoleh $\mathrm{r}=0,6738$. Hasil pengujian terhadap koefisien $\mathrm{r}$ diperoleh $T_{\text {hit }}=7,52$. Karena $T_{\text {hit }}=7,52 \quad T_{\text {tabsl }} \quad(\alpha / 2=5 \% \mathrm{db}=68)=1,99$ maka tolak $H_{0}$ ( terima $H_{1}$ ) artinya kebutuhan petani dalam pelaksanaan usahatani padi sawah berhubungan secara nyata dengan sistem pengelolaan gilir ganti padi sawah di Desa Mukai Mudik.

\section{Hubungan Kebutuhan Petani Berdasarkan Sosial Dengan Sistem Pengelolaan Gilir Ganti Padi Sawah.}

Berdasarkan hasil penelitian yang dilakukan mengenai hubungan kebutuhan petani berdasarkan kebutuhan sosial dengan sistem pengelolaan gilir ganti padi sawah dapat lihat pada Tabel 13. 
Tabel 13. Kontingensi Kebutuhan Petani Berdasarkan Sosial Dengan Sistem Pengelolaan Gilir Ganti Padi Sawah.

\begin{tabular}{ccccc}
\hline Sistem Gilir & \multicolumn{3}{c}{ Motivasi Petani } & Jumlah \\
\cline { 2 - 4 } Ganti & Tinggi & Sedang & Rendah & \\
\hline Tinggi & 20 & 18 & 14 & 52 \\
Rendah & 6 & 4 & 8 & 18 \\
Jumlah & 26 & 22 & 22 & 70 \\
\hline
\end{tabular}

Tabel 13 memperlihatkan hubungan kebutuhan petani berdasarkan kebutuhan sosial dengan pelaksanaan usatahani dengan sistem pengelolaan gilir ganti padi sawah di daerah penelitian, yaitu ada kecendrungan jika kebutuhan sosial tinggi maka tingkat pelaksanaan usahatani dengan sistem pengelolaan gilir ganti tinggi.

Berdasarkan uji statistik non parametrik dengan menggunakan uji Chi-square di peroleh nilai $X^{2}$ hit $=30,27$ dengan nilai $X^{2}$ tabel $(\alpha=5 \% \mathrm{db}=2)=5,99$. Karena $X^{2}$ hit $=30,27>X^{2}$ tabel $(\alpha=5 \% \mathrm{db}=2)=5,99$ maka diputuskan tolak $H_{0}$ (terima $H_{1}$ ), yang berarti tinggi rendahnya kebutuhan petani mempengaruhi tinggi rendahnya pelaksanaan usahatani dengan sistem pengelolaan gilir ganti padi sawah. Derajat kontingensi kebutuhan petani dengan pelaksanaan usahatani dengan sistem pengelolaan gilir ganti padi sawah adalah $C_{\text {hit }}=0,549$ dan $C_{\text {maks }}=0,8164$. Hal ini artinya derajat kecendrungan kebutuhan petani dengan pelaksanaan usahatani dengan sistem pengelolaan gilir ganti padi sawah adalah 54,9 persen. Kecendrungan hubungan antara kebutuhan petani dengan pelaksanaan usahatani dengan sistem pengelolaan gilir ganti padi sawah tergolong kuat dimana nilai $\mathrm{C}=0,549$ (berada antara $0,4082-0,8164$ ). Sedangkan pengukuran derajat korelasi antara perbedaan kebutuhan petani dengan pelaksanaan usahatani dengan sistem pengelolaan gilir ganti padi sawah diperoleh $r=0,673$. Hasil pengujian terhadap koefisien $\mathrm{r}$ diperoleh $T_{\text {hit }}=7,5$. Karena $T_{\text {hit }}=7,5 T_{\text {tabel }} \quad(\alpha / 2=5 \%$ $\mathrm{db}=68)=1,99$ maka tolak $H_{0}\left(\right.$ terima $\left.H_{1}\right)$ artinya kebutuhan petani dalam pelaksanaan usahatani padi sawah berhubungan secara nyata dengan sistem pengelolaan gilir ganti padi sawah di Desa Mukai Mudik.

Hubungan Kebutuhan Petani Berdasarkan Pengakuan Dengan Sistem Pengelolaan Gilir Ganti Padi Sawah.

Berdasarkan hasil penelitian yang dilakukan mengenasi hubungan kebutuhan petani berdasarkan kebutuhan pengakuan dengan sistem pengelolaan gilir ganti padi sawah dapat lihat pada Tabel 14.

Tabel 14. Kontingensi Kebutuhan Petani Berdasarkan Pengakuan Dengan Sistem Pengelolaan Gilir Ganti Padi Sawah.

\begin{tabular}{ccccc}
\hline \multirow{2}{*}{ Sistem Gilir } & \multicolumn{3}{c}{ Motivasi Petani } & \multirow{2}{*}{ Jumlah } \\
\cline { 2 - 4 } Ganti & Tinggi & Sedang & Rendah & \\
\hline Tinggi & 25 & 16 & 11 & 52 \\
Rendah & 4 & 7 & 7 & 18 \\
Jumlah & 29 & 23 & 18 & 70 \\
\hline
\end{tabular}

Tabel 14 memperlihatkan hubungan kebutuhan petani berdasarkan kebutuhan pengakuan dengan pelaksanaan usahatani dengan sistem pengelolaan gilir ganti padi sawah di daerah penelitian, yaitu ada kecendrungan jika kebutuhan pengakuan tinggi maka tingkat pelaksanaan usahatani dengan sistem pengelolaan gilir ganti tinggi.

Berdasarkan uji statistik non parametrik dengan menggunakan uji Chi-square di peroleh nilai $X^{2}$ hit $=30,66$ dengan nilai $X^{2}$ tabel $(\alpha=5 \% \mathrm{db}=2)=5,99$. Karena $X^{2}$ hit $=30,66>X^{2}$ tabel $(\alpha=5 \% \mathrm{db}=2)=5,99$ maka diputuskan tolak $H_{0}$ (terima $H_{1}$ ), yang berarti tinggi rendahnya kebutuhan mempengaruhi tinggi rendahnya pelaksanaan 
usahatani dengan sistem pengelolaan gilir ganti padi sawah. Derajat kontingensi kebutuhan petani dengan pelaksanaan usahatani dengan sistem pengelolaan gilir ganti padi sawah adalah $C_{\text {hit }}=0,5519$ dan $C_{\text {maks }}=0,8164$. Hal ini artinya derajat kecendrungan kebutuhan petani dengan pelaksanaan usahatani dengan sistem pengelolaan gilir ganti padi sawah adalah 55,19 persen. Kecendrungan hubungan antara kebutuhan petani dengan pelaksanaan usahatani dengan sistem pengelolaan gilir ganti padi sawah tergolong kuat dimana nilai $\mathrm{C}=0,5519$ (berada antara 0,4082-0,8164). Sedangkan pengukuran derajat korelasi antara perbedaan kebutuhan petani dengan pelaksanaan usahatani dengan sistem pengelolaan gilir ganti padi sawah diperoleh $\mathrm{r}=0,676$. Hasil pengujian terhadap koefisien $\mathrm{r}$ diperoleh $T_{\text {hit }}=7,564$. Karena $T_{\text {hit }}=7,564 T_{\text {tabsl }} \quad(\alpha / 2=$ $5 \% \mathrm{db}=68)=1,99$ maka tolak $H_{0} \quad\left(\right.$ terima $\left.H_{1}\right)$ artinya perbedaan kebutuhan petani berhubungan nyata dengan pelaksanaan usahatani dengan sistem pengelolaan gilir ganti padi sawah.

\section{Hubungan Kebutuhan Petani Berdasarkan Aktualisasi Diri Dengan Sistem Pengelolaan Gilir Ganti Padi Sawah}

Berdasarkan hasil penelitian yang dilakukan mengenasi hubungan kebutuhan petani berdasarkan kebutuhan aktualisasi diri dengan pelaksanaan usahatani dengan sistem pengelolaan gilir ganti padi sawah dapat lihat pada Tabel 15.

Tabel 15. Kontingensi Kebutuhan Berdasarkan Aktualisasi Diri Dengan Sistem Pengelolaan Gilir Ganti Padi Sawah.

\begin{tabular}{ccccc}
\hline Sistem Gilir & \multicolumn{3}{c}{ Kebutuhan Petani } & \multirow{2}{*}{ Jumlah } \\
\cline { 2 - 4 } Ganti & Tinggi & Sedang & Rendah & \\
\hline Tinggi & 20 & 15 & 17 & 52 \\
Rendah & 6 & 8 & 4 & 18 \\
Jumlah & 26 & 23 & 21 & 70 \\
\hline
\end{tabular}

Tabel 15 memperlihatkan hubungan kebutuhan petani berdasarkan kebutuhan aktualisasi diri dengan pelaksanaan usahatani dengan sistem pengelolaan gilir ganti padi sawah di daerah penelitian, yaitu ada kecendrungan jika kebutuhan aktualisasi diri tinggi maka tingkat pelaksanaan usahatani dengan pengelolaan gilir ganti tinggi.

Berdasarkan uji statistik non parametrik dengan menggunakan uji Chi-square di peroleh nilai $X^{2}$ hit $=30,18$ dengan nilai $X^{2}$ tabel $(\alpha=5 \% \mathrm{db}=2)=5,99$. Karena $X^{2}$ hit $=30,18>X^{2}$ tabel $(\alpha=5 \% \mathrm{db}=2)=5,99$ maka diputuskan tolak $H_{0}$ (terima $H_{1}$ ), yang berarti tinggi rendahnya kebutuhan petani mempengaruhi tinggi rendahnya pelaksanaan usahatani dengan sistem pengelolaan gilir ganti padi sawah. Derajat kontingensi kebutuhan petani dengan pelaksanaan usahatani dengan sistem pengelolaan gilir ganti padi sawah adalah $C_{\text {hit }}=0,5489$ dan $C_{\text {maks }}=0,8164$. Hal ini artinya derajat kecendrungan kebutuhan petani dengan pelaksanaan usahatani dengan sistem pengelolaan gilir ganti padi sawah adalah 54,89 persen. Kecendrungan hubungan antara kebutuhan petani dengan pelaksanaan usahatani dengan sistem pengelolaan gilir ganti padi sawah tergolong kuat dimana nilai $\mathrm{C}=0,5489$ (berada antara 0,4082-0,8164). Sedangkan pengukuran derajat korelasi antara perbedaan kebutuhan petani dengan pelaksanaan usahatani dengan sistem pengelolaan gilir ganti padi sawah diperoleh $r=0,67235$. Hasil pengujian terhadap koefisien $\mathrm{r}$ diperoleh $T_{\text {hit }}=7,49$. Karena $T_{\text {hit }}=7,49 T_{\text {tabsl }} \quad(\alpha / 2=$ $5 \% \mathrm{db}=68)=1,99$ maka tolak $H_{0} \quad\left(\right.$ terima $\left.H_{1}\right)$ artinya kebutuhan petani dalam pelaksanaan usahatani padi sawah berhubungan secara nyata dengan sistem pengelolaan gilir ganti padi sawah di Desa Mukai Mudik.

\section{Kesimpulan}


Usahatani dengan sistem pengelolaan gilir ganti padi pada umumnya masih melaksanakan sistem gilir ganti sawah, meskipun manfaat dari sistem ini tidak begitu berdampak terhadap pengguna sistem ini. Hal ini disebabkan karena sawah gilir ganti dianggap sebagaimana ikatan keluarga, sarana memperkuat silaturahmi, menjaga martabat keluarga.

Dari hasil penelitian yang telah dilakukan, maka diperoleh beberapa kesimpulan. Berdasarkan analisis deskriptif, maka didapat kesimpulan bahwa, kebutuhan akan pengakuan yang menjadi kebutuhan tertinggi petani dalam melaksanakan usahataninya, yaitu sebesar 75,77 persen, dan kebutuhan terendah yaitu kebutuhan sosial sebesar 68,42 persen. Kebutuhan fisik 73 persen, kebutuhan rasa aman 71,28 persen, dan kebutuhan aktualisasi diri 74 persen. Ini menunjukkan bahwa kebutuhan pengakuan merupakan indikator tertinggi dalam melaksanakan usahataninya, yang mana untuk memenuhi kebutuhan hidupnya sehari-hari dibandingkan indikator kebutuhan yang lainnya.

Kebutuhan petani dalam pelaksanaan usahatani dengan sistem pengelolaan gilir ganti sawah berhubungan secara nyata dengan penerapan usahatani dengan sistem pengelolaan gilir ganti padi sawah.

\section{UCAPAN TERIMA KASIH}

Terimakasih disampaikan kepada yang terhormat Bapak Camat Kecamatan Siulak Mukai, Kepala Desa Mukai Mudik, Ketua Kelompok tani beserta semua anggota kelompok Tani Tengah Padang yang telah membantu dalam penelitian ini dan penyuluhan Kecamatan Pemayung yang telah membantu saya dalam pengambilan data penelitian.

\section{DAFTAR PUSTAKA}

Fadholi Hernanto. 1991. Ilmu Usaha Tani. Penebar Swadaya. Jakarta

Hamzah BU. 2011. Teori Motivasi dan Pengukurannya: Analisis di Bidang Pendidikan.

Bumi Aksara. Jakarta

Handoko Hani. 1996. Manajemen dan Sumberdaya Manusia. BPFE. Yogyakarta

Hasibuan Malayu. 1996. Organisasi dan Motivasi \& Dasar-dasar Peningkatan Produktivitas. Bumi Aksara. Jakarta

Hariandja MTE. 2007. Manajemen Sumberdaya Manusia. Grasindo. Jakarta

Ibrahim. 2012. Motivasi Petani Dalam Pelaksanaan Program Pengelolaan Tanaman Terpadu PTT Padi Sawah di Kecamatan Pengabuan Kabupaten Tanjung Kabung Barat. Skripsi S1. Jurusan Agribisnis. Fakultas Pertanian. Universitas Jambi.

Idris Isran. 2011. Pola Penguasaan Tanah Sawah Secara Gilir Ganti Pada Masyarakat Hukum Adat Kerinci. Jurnal Ilmu Hukum Unja. Jambi

Miles MB., Huberman, AM. 2009. Analisis Data Kualitatif Buku Sumber Tentang Metode-metode Baru (diterjemahkan oleh Tjeptjep Rohandi Rohidi). UIP. Jakarta

Ridwan dan Akdon. 2009. Metode dan Teknik Menyusun Proposal Penelitian. Alfabet. bandung

Siegel Sidney. 1992. Statistik Nonparametrik Untuk Ilmu-ilmu Sosial. Gramedia. Jakarta. Siregar Hardian. 1987. Bercocok Tanam Padi di Indonesia. Sastra Husada. Jakarta

Sugiono. 2009. Memahami Penelitian Kualitatif. Alfabeta. Bandung

Sugiono. 2009. Metode Penelitian Kualitatif dan R\&D. Alfabeta. Bandung

Prayogi ED. 2013. Motivasi Kebutuhan Petani Melaksanakan Pengelolaan Tanaman Terpadu (Ptt) Pada Usahatani Padi Sawah Dan Faktor Sosial Ekonomi Yang Mempengaruhinya. Skripsi S1. Jurusan Agribisnis. Fakultas Pertanian. Universitas Jendral Soedirman. 